\title{
Classification and Cataloging of Spoken Records in Academic Libraries
}

\begin{abstract}
There are at least eight satisfactory systems for assigning shelf locations to spoken-word phonodiscs in academic libraries. The advantages and disadvantages of each are considered. Problems are also discussed in the cataloging of such materials. Separate vs. integrated catalogs; color vs. other coding devices; LC vs. homemade catalog cards, are among topics explored.
\end{abstract}

A

Librarian who finds himself suddenly saddled with the job of establishing a usable collection of spoken-word phonograph and tape recordings may regard his chore either an albatross or an adventure. If he adopts the first attitude, there is little hope for him or for the collections; if the latter, it will be just that. The almost endless list of choices and decisions offers challenges to the stronghearted somewhat akin to those presented to Ulysses. And of all of them, the two which probably require the greatest amount of foresight are the classification and cataloging procedures to be used in his collection. This article will treat each of these separately.

Classification. Before choosing a classification system for a record collection, there are many things which the librarian must take into account. The fact that there are at least eight classification schemes, all of which seem to be used with equal satisfaction in different libraries, indicates that the physical and, perhaps, psychological aspects of the library, the librarian, and the collection have a substantial influence on the system finally employed.

Often, as with books, the larger the

Mr. Barnes is College Librarian, Keene State College, Keene, New Hampshire. collection, the more involved the classification system becomes. The classification scheme in a collection of five thousand albums is likely to be far more complex than that used in a collection of five hundred albums. With the former, there is apt to be much more repetition of authors and titles, requiring as a result longer letter and number combinations.

Another factor to be weighed is the accessibility of the collection to its users. If the albums are shelved in open stacks, it is advisable that they be shelved in much the same arrangement as are the library's books, for that is what the patrons are accustomed to. To shelve them by accession number or by publisher would make browsing a fruitless endeavor because the borrower interested in poetry would have to look over the entire collection to see what poetry was available.

On the other hand, if the patrons do not have access to the record stacks, it is obvious that a classification scheme designed for easy browsing would be totally wasted.

Academic libraries, as a rule, tend to look at their record collections as permanent or, at least, long-range investments. Desiring to protect them from the common ravages of circulation, these li- 
braries usually regulate their use with the fiercest zeal. For this reason, it shall be assumed that the collection here under discussion is to be kept in closed stacks.

In a very small collection, up to 150 albums, an elementary system may be used whereby the records are given no call number at all but are simply shelved by the main entry on the catalog card.

- Another easy classification scheme which can be successfully applied to a somewhat larger collection is the one in which the speed and size of the disc determine the call number. Used with an accession number, a call number such as "161-12-33" would designate the 161st twelve-inch, long-playing record added to the collection. In this case, the records would be shelved according to size.

The uncomplicated method of fixed location may also be used for a small and relatively static collection. In this system, a record or album would be given the number "7.12" if it were the twelfth disc from the left on shelf number seven.

A fourth system of notable simplicity which also allows for expansion involves the use of a physical-form letter ( $D$ for a disc and $T$ for a tape) plus the accession number. Thus, you would give the call number "D 307" to the 307th disc acquired by the library, regardless of its speed or size.

If, for any reason, the librarian wishes to gather together all the works of a particular type and subdivide by author, a system can be utilized in which a form letter, such as P for poetry, is followed by a Cutter number. An example of this would be, for two poetry readings of Conrad Aiken, $\mathrm{P}_{\mathrm{A} 29}$ and $\mathrm{P}_{\mathrm{A} 291}$. If the col-

lection includes tapes as well as discs, the physical-form notation can easily be added.

Similar to this, but slightly more involved, is the one which uses a classifica- tion number from Dewey. This system will bring together recordings of a like nature in addition to separating English poetry from French poetry, and so forth. In this scheme, the Aiken recording would be assigned the number 811 . In A29

a closed stack situation, however, the need for dividing nationality groups is usually negligible.

For the traditionalist, who will insist on complication at any cost, a system may be adopted which consists of Cutter numbers for both author and title. Above these two numbers, the physical form designation would be used. For example, the Aiken recording entitled, A Letter from $\mathrm{Li} \mathrm{Po}$, would be given the call number DISC.

\section{A29 \\ L6}

Anthologies could be divided into a "Z" category with "Z1" specifying poetry anthologies, "Z2" drama, "Z3" speeches, and so on. In this system, the recording entitled, Great American Speeches, would bear the number DISC. In the Z7

event that, say, poetry and drama are combined in a single anthology, the librarian would simply make a choice between the two and classify it under "Z1" or "Z2."

The classification scheme used in Cornell's listening rooms is based upon the manufacturer's serial number for any given disc or album. There is no effort to consolidate the works of any author or any particular literary genre into any one section of the closed stack area.

Within the manufacturer's group, the albums are arranged in sequence by the number which every record company gives its discs. For example, holdings in the Caedmon productions include Herbert Marshall reading Donne's sermons (TC 1051), Robert Graves reading some of his own poems (TC 1066), and Cocteau's play, The Human Voice (TC 1118). These recordings are shelved in 
that order in the space devoted entirely to Caedmon discs.

Since Cornell's collection includes both discs and tape, the call number assigned to the Graves recording is DISC CAEDMON ${ }^{\circ}$ TC 1066

It should be mentioned here that, besides the great simplicity of this system, there is the added advantage of having the same basic call number appear on the disc, the record jacket, the LC printed cards, all the manufacturers' catalogs, and the catalogs of Schwann and similar companies.

Dozens of other systems might be explored here, since the classification of phonodiscs seems to evoke the Muse of Originality, but at least one of the eight methods described above should prove most adequate to answer the needs of practically any library.

Cataloging. The cataloging of a library's collection of nonbook materials always requires special planning. In establishing a useful library of phonodiscs, it is usually discovered that their physical composition only serves to augment the problems of the catalog librarian.

Phonodisc albums, because they rarely have spines wide enough for the printing of clearly legible titles or call numbers, do not easily lend themselves to convenient and productive browsing for the potential listener. Indeed, the lack of a well-printed spine often inhibits speedy retrieval of the disc from the stacks and encourages shelving errors if extra care is not taken. By far, then, the easiest key to the use of the collection is the card catalog. As a result, the cataloger assumes a tremendous importance in the fruitful functioning of the collection.

In a closed stack situation especially, it is clear that the catalog must be well devised and supplied with an abundance of added entries if the collection is to be used to its fullest potential. Most of the early phonodisc libraries were cataloged simply, with from one to three cards for each album being filed into a special drawer set apart from the book catalog. These collections were truly the step-children of their respective libraries.

Actually, few libraries could, or would want to, boast of record holdings large enough to warrant equal status with their book collections. But a great many libraries now have, or are developing, phonodisc collections which not only deserve full and detailed cataloging, but which also demand integration within the general catalog as well, if they are to fulfill their potential role in the educational process.

The Library of Congress, with its comparatively recent introduction of the Music and Phonorecord supplement to its Catalog, is doing its share in bringing about the recognition of phonograph records as an educational as well as an entertaining medium.

Printed semi-annually, with annual and quinquennial cumulations, this supplement does for discs what the main section does for books, noting subject headings and added entries for all recordings which have been entered at the library. Because of their fairly extensive coverage, and because of the easy availability of LC cards, many libraries have switched, without a fight, from their own individualistic, and often inadequate, cataloging methods to the LC system, most of them using the LC cards.

When Cornell's listening rooms began operations, the LC cards were used whenever available. Later, however, it was decided that they included many things which were not needed and excluded many things that were felt to be necessary, such as complete analysis of all recordings, including multi-poem discs. The use of LC cards at Cornell was therefore discontinued. Other libraries will have to make up their own 
minds on this point. It should be noted, for the music librarian, that LC's music record coverage is far more comprehensive than its spoken-word coverage.

A second area of decision for the librarian is the allocation of the cards once they are prepared. In small collections a separate file is often maintained. At least one person doing research has found that only a minority of librarians advocate the placement of catalog cards for phonodiscs in the main catalog with their book cards. Those librarians, however, who have maintained an integrated catalog have found an increased use of their record collections. The ideal seems to be inclusion of phonodisc cards in the main book catalog as well as in a separate file located in the area where the records will be played.

In an integrated catalog it is advisable, when there is a work in both printed and recorded form, to place the cards for the recording in front of the corresponding book cards. Since many library patrons are not accustomed to seeking out phonodiscs, especially in the spokenword field, they are much more likely to notice that there is a recorded version of the work they are seeking if the record card comes first. If the card for the disc were filed behind the book cards, the patron would probably never get to it but would stop when he got to the book card.

At this point, it should be mentioned that some librarians have found it expedient to use a system of colored catalog cards for phonograph record catalog- ing. The primary advantage of this practice is that it makes it immediately apparent that the card refers to a recording rather than to a book. Unfortunately, there is often a tendency to broaden the system so that, for instance, there is one color for musical recordings and a second for non-musical recordings; then another color is added for non-musical recordings in a foreign language, and so on. Eventually there are so many different colors that their usefulness as instant transmitters of specific information is almost completely negated.

Also, the experience in more than one library has been that after a year or two it is decided that the original reason for using a blue card, for instance, is not as important as it was thought to be. The library then returns to using only white cards and the resultant combination of white and blue cards meaning the same thing only creates confusion in the patrons who, understandably, assume that the cards mean different things.

These are a few of the problems that must be met and solved before a phonodisc collection may assume its proper role in the library's over-all holdings. If solutions are not found at the outset, it will be more difficult to make the necessary adjustments when the collection reaches large proportions. And in this day of increasing production and excellence by phonodisc manufacturers, it is becoming increasingly difficult to maintain a record collection which is at the same time small and good.

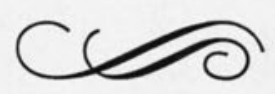

